\title{
Path to the Development in Oil-Painting in Vietnam
}

\author{
Nguyen Van Doan (Wentuan Ruan) \\ School of Art Hunan Normal University, Changsha City, Hunan, China \\ Ho Chi Minh City University of Fine Arts, Ho Chi Minh City, Vietnam
}

\begin{abstract}
From the ancient time, when knowing how to draw, humans deliberately sought for good materials for drawings and wish their colors to be durable. Also from the ancient age, we, humans, knew to mix colors with oil to draw. Materials at the time, however, were very gross with many shortcomings and limitations. Over the time, many generations of painters have taken great pains to search for materials and craped for paint. Nevertheless, only until the age of Van Eyck brothers (around 1390-1441) they gained great success in accomplishing and developing oil-painting techniques. Oil-painting colors until this age got purer, brighter, shinier, waterproof, sustainable, and endurable with time. Since then, oil-paint has been widely used in almost countries worldwide. It can be said that the accomplishment of oil-paint is a great technical revolution that changes and enhances the picture painting art. The painting of oil in English means oil painting. It is the kind of the most popular and favorite pictures. It is called as the name of painting material. That is the oil paint that can be drawn on wooden, metal, and canvas surfaces, etc., Oil kinds with different materials will bring about kinds of oil paints with differentiated attributes. Oil paintings by Indian painters firstly appeared in those on Buddhism and they came to China from the 5th to 10th centuries but only until the 15th century, oil paintings got popular and developed. Oil paint finally became the key tool for painters to transfer into artistic works.
\end{abstract}

Keywords: Vietnam oil paintings, the formation of roads

\section{Vietnam's Oil Paintings in the Early 20th Century (1900-1925)}

Being regarded as the pioneer painters of oil paintings in Vietnam to access the oil paint material, three painters: Le Van Mien, Thang Tran Phenh, and Nam Son have left special hallmarks and first "bricks" to build up oil paint "foundation" in Vietnam.

\section{The Spirit of Confucianism by Le Van Mien Painter}

So far, many documents on Vietnam's history of fine art have still recorded that the painter Le Van Mien (or Le Huy Mien, 1873-1943) is the first painter who gained the Western study as well as one of the five abroad students assigned by Hue Court to France to learn at the Colonial School. In 1891, he entered Paris Fine Art School. Very few works by the painter Le Van Mienhave remained. Besides the two oil paintings at Vietnam Fine Arts Museum titled as "Tu Men Great Grandfather" (in 1895) (see Figure 1) and "Comments on Literature" (in 1898), there is another work "Portrait of Lê Hy Great Grandfather" (from 1895-1897/oil painting).

Van-Doan Nguyen (Wentuan Ruan), Doctoral Student, School of Art Hunan Normal University; Ho Chi Minh City University of Fine Arts, Ho Chi Minh City, Vietnam. 


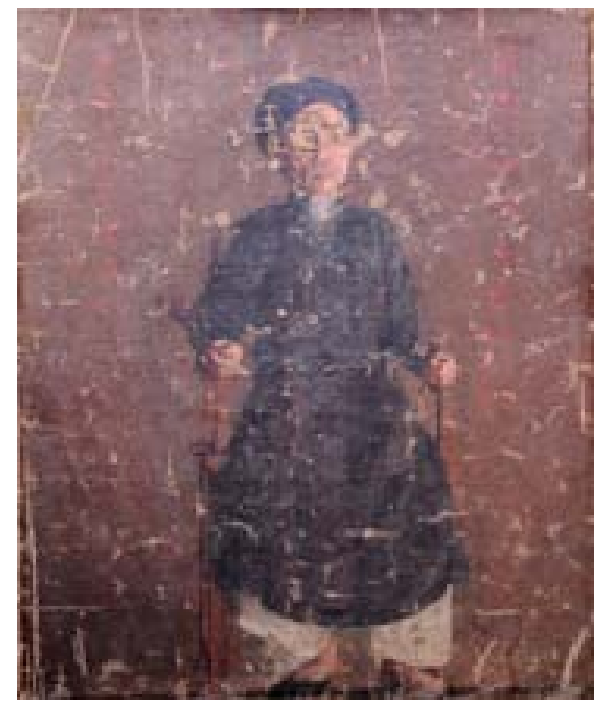

Figure 1. Portrait of Tu Men Great Grandfather, the oil painting, in 1895 (by Le Van Mien).

The technique and figure of the character in "Tu Men Great Grandfather" and "Comment on Literature" show that he had learnt about oil painting and applied the anatomy and Western principle, however, the spirit still belongs to the last students of Vietnam. The oil painting of "Tu Men Great Grandfather" was drawn on oil paint material but shares the joint-spirit with the portrait drawing during the early 20th century. It is the tiny portrait of the old man who sits, leaning on the chair, wearing a Cassock, turban, and white flax trousers. The outstanding point in this work lies in the painter's skillful color combination. The old man in the portrait appears with a dignified and serious spirit of a Confucian Scholar. However, the cosy pink color spreads from the face down to hands and the gap between his feets (between the trousers and shoes), even spreading the background, which makes the two lines of words in light red, etc., outstanding. All of these uphold the solemn respectfulness and the spirit of Confucianism of the painted person. The color combination shows the painter's respect toward his mastetr. The picture does not simply show experiences of colors, drawing, and layout, etc., deeply, including gratitude and respect toward the prototype. This is the joint-spirit in portraits by Le Van Mien. It shows that the painter himself does not really separate himself from the traditional culture deeply inside his consciousness. Only until he drew the oil paint titled "Comments on Literature" (see Figure 2), audiences really realized more of flexibility and dark-bright combination to create depth, block formation, and the layout of three characters with different postures, actions, and psychological tones. This shows the painter learnt much from the Realistic European Painting. However, in comparison of colors, the drawing technique in the picture of "Comments on Literature" is much different from that of the remaining pictures by Le Van Mien. If comparing it with the "Tu Men Great Grandfather", "Comments on Literature" has not been accomplished yet. In other words, it has not got "full" in terms of colors. However, the work's attractive point that makes the name of Le Van Mienas the pioneer in Vietnam's oil painting drawing lies in the exclusive feature of the work. "Comments on Literature" evokes audiences the scenario of Literature on Confucianism at the end of the 19th-early 20th century. Although the colors in the picture are not "sufficient" yet partly influential on the color in pictures by painters during the period of Indochina Fine Arts later, typically the painter Nguyễn Phan Chánh (1892-1984). Several young generations often call it as the color of soil. In general, the neutral color in "Comments on Literature" is much influenced by Vietnam's traditional folk fine arts, specifically, the 
traditional lacquer painting. There are eight people in the picture, including: a teacher, six disciples, and one little boy who tries to pick up the taught things. The group of disciples is in white fabric scarfs and Cassock, which is so serious together with the image of the little boy who picks up knowledge. This reminds much about the Vietnamese tradition of eager to learn. The picture's layout also brings about distinction. "Comments on Literature" is completely far away from the folk decoration and estimates that inherently control the Vietnamese's painting form. In "Comments on Literature", audiences can feel the clear overlapping between Eastern-Western cultures through colors, forms, and layouts in pictures.

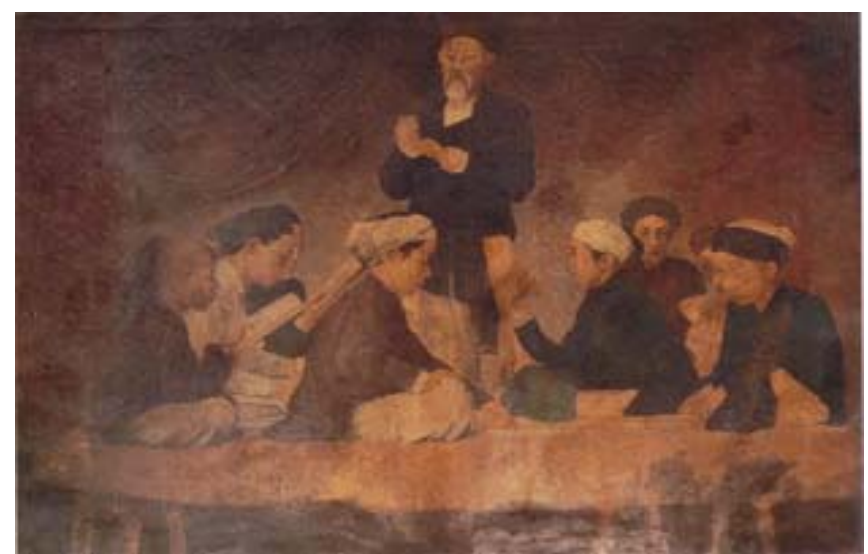

Figure 2. Comments on Literature, the oil painting, in 1898 (by Le Van Mien).

Because of too long time and over the two Resistances for national protection by the Vietnamese Race, works by the painter Le Van Mien have not remained many. Besides the two above-mentioned works bought back by Vietnam Fine Arts Museum, the remaining works are scattered at collectors' places and belong to individuals of Lê family, etc., Among the remaining works so far, the Vietnamese are still proud of their "predecessors". Despite of slow steps toward the professional drawing in general and the oil painting in particular, they still gain their own voices with lessons from Western formation and simultaneously, applying the traditional culture of Vietnam for creativity, thence, creating distinction in works.

The first step in Vietnam's modern painting in general and oil painting in particular is regarded as a slow one. Meanwhile, the Vietnamese can only see and feel "cream/essence" from handcrafts, etc., right from the beginning, when meeting the Vietnamese, the French supposed that "the Annamese are just light-fingered only but little creative in fine arts". Our country was compared with such East Asian countries of superior national cultural development as China, Japan, South Korea, etc. Besides, the folk art in Vietnam has developed so much. The village culture has prevailed all progressive creativity, made it dim, even spoiling it as well as accessing winds of Western culture and arts.

\section{Vietnam's Specific Traits in the Oil Paintings by the Painter Nam Son}

The painter Nam Son (1890-1973) was also called as Nguyễn Nam Sonor Nguyen Van Tho-the co-founder of Indochina Fine Arts College. Like the painter Le Van Mien, he was trained with the professional fine art at Paris Fine Arts School in France. With the oil paint, the painter Nam Son mainly drew portraits with both realistic and impressive style. The Vietnamese remember Nam Sonas both a teacher and painter. During his lifetime, he ever left an autograph when co-founding the first professional fine arts school; “...Setting up a school where talented painters were trained and preserving the fine arts inheritted from the ancesstors in order to better and form the Indochina fine arts with Vietnam's specific traits, etc.". 
Vietnam's specific traits are expressed through the work "The Northern Confucian Scholar" (see Figure 3) that partly shows the Vietnamese in works during the dawn of oil paintings. With a mixture of style between realistic and impressive, the painter Nam Son craved a portrait of a man of around sixty years old, wearing a white scarf. His face shows determination and strong wills. His left hand with gentle fingers and long nails raised up to stroke the long grey beard. The realistic style is conveyed in the depiction of portraits through the determined and focused eyes often seen in those who pursue Confucianism. In addition, the realistic style is also shown in other such details as shrinking eyebrows, a high nose-slightly big ala nasi, broad forehead, phlyctenular, wrinkles, and those due to skin sagging, which shows the old age. The mouth is wide while the hands are long and a bit rugged, etc., these are the features of the Annamese. The impressive style is shown through the way the painter utilized colors. By changing colors and focusing on the "pursuit" of lights over almost details of the picture, the light path via lime's white color on the turban, dim white color on the forehead, silver color on the ala nasi and dorsonasal, grey white on the beard, white mixed with brown on fingers and nails, etc., can be seen. The move of colors is often seen in the style of painters who shape the Impressive painting.

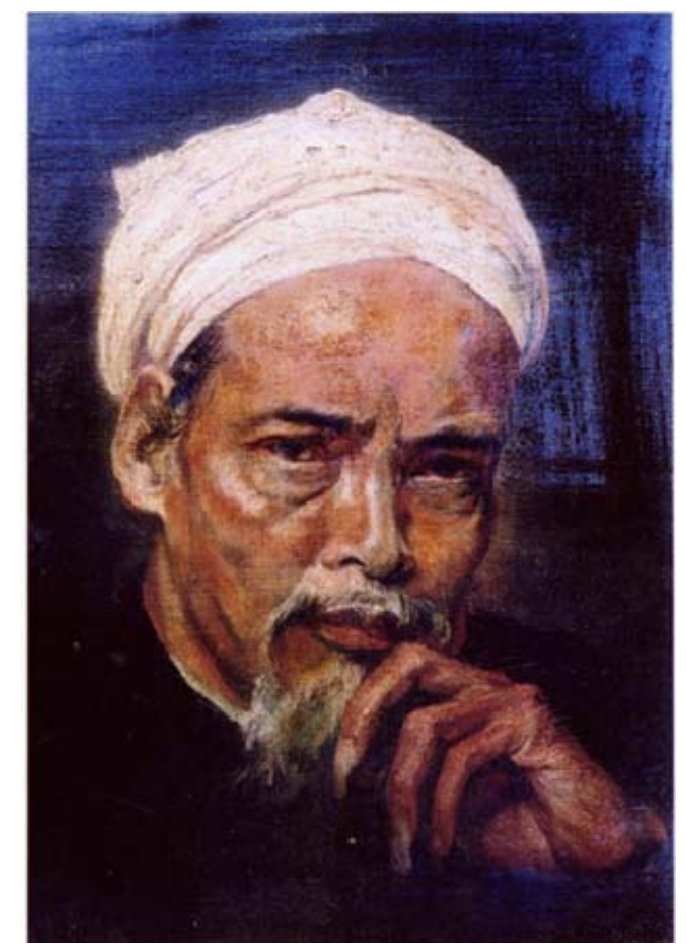

Figure 3. The Northern Confucian Scholar, the oil painting (by Nam Sơn).

The skill of observation and color utilization by painters based on "The Northern Confucian Scholar" can partly be visualized. It is the rather thorough study on prototype and the good grasp of not only the figure but also the inner mien and thoughts of the portrayed person. In the transitional age of history, culture and arts in Vietnam, when there is not much "wide field of action" for Confucianism, their preoccupation lies in the brow knit, determined yet challenging eyes as if asking something. The painter Nam Son is very skillful when understanding the character's inner feelings and utilizing the Western painting technique in one work. In "The Northern Confucian Scholar", audiences easily realize the overlapping between the Eastern-Western cultures. 
Like the painter Le Van Mien who takes full advantages of the Western painting technique to "tell" the story on Vietnam and the Vietnamese in the most sincere manner through the image of the Confucian Scholar.

\section{Familiar and Simple Topic in Pictures by Thang Tran Phenh}

Unlike the other two painters: Le Van Mienand Nam Son, the painter Thang Tran Phenh (1895-1963) learnt how to draw on himself, however, gained the early success at the age of 18, his picture "Colonial Fair". For painting in general, pictures by Thang Tran Phenh are much applied on stages. Later, Thang Tran Phenh was taught by a French person on oil painting techniques with the first one titled as "Phạm Ngũ Lão" (1923) and "the Laos girl" (1923).

Based on topic selection for oil paintings by the painter Thang Tran Phenh, audiences can rightly feel the absence of Confucianism. The painter chooses the historical heroes (Pham Ngu Lao) and the commoner in the daily life (the Laos girl) sincerely. The work "Pham Ngu Lao" is considered as pioneer historical of oil paintings in Vietnam. Based on the legend of this hero, his bravery, and heart for the national destiny, details in the story are all narrated on the picture's surface, which makes the work more oriented toward the illustration rather than an artistic work. This is also the shortcoming of Thang Tran Phenh. This shows in the context of East-West integration, he was not really ready to further beautify and clarify his expression methods. This shows about the step in Vietnam's painting in general and the oil painting in particular. However, in the same year of 1923, Thang Tran Phenh drew one more portrait "The Laos girl" (see Figure 4) with a rather novel layout and topic compared with those of traditional fine arts at the time. Despite of some forces in the background color, face, and shirt's color changing, the work still offers many outstanding points. With an inclining angle of $3 / 4$, it often creates a more interesting angle of view to painters when drawing from the front or half inclining. In "The Laos girl", the painter Thang Tran Phenh paid much attention to graphics and focused on the realistic depiction to make all the details in the picture outstanding. The formation of the character's face was rather premature in terms of color and graphical treatment. The painter created a block of brightness and darkness but not as focusedly and skillfully as that in "The Northern Confucian Scholar" by the painter Nam Sonor not as clear and humorous as that in the work "Tu Men Great Grandfather" by the painter Le Van Mien.

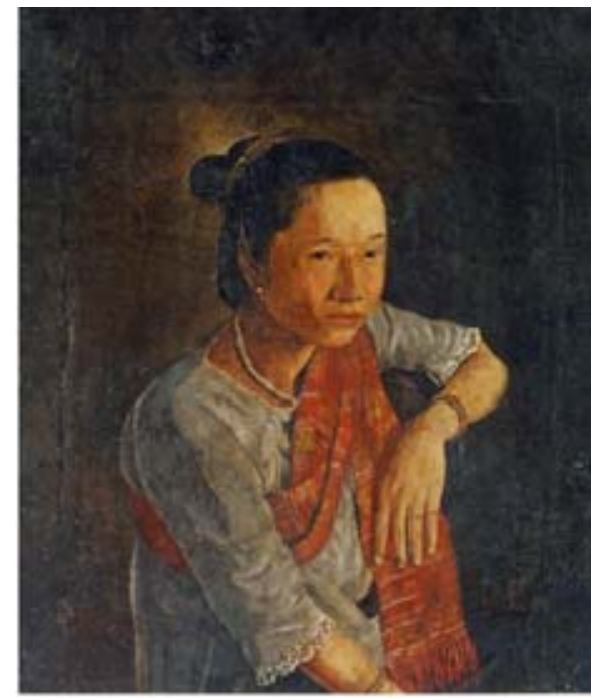

Figure 4. The Laos girl, the oil painting, 1923 (by Thang Tran Phenh). 
The thing that makes audiences admire lies in the strong-will of the painter Thang Tran Phenh who did not officially learn how to draw at any classes but learnt to draw oil paintings through words of mouths from a French friend. This is also regarded as a remarkable achievement. The layout of the picture "The Laos girl" is rather eye-catching, which shows the painter's smartness when choosing the character's sitting angle. If ignoring the shortcomings in color treatment techniques, this is a great success by the painter Thang Tran Phenh.

\section{Conclusion}

During the first access to the oil painting art, all the three painters: Le Van Mien, Nam Sơn, and Thang Tran Phenh created their own distinctive style. In works by the three painters, they are not only acknowledged as the pioneers in Vietnam's painting and fine arts but also changers in the fine arts. They bring about innovation and changes in artistic creativity and methods. Although it is a slow change, contributions by the three painters Le Van Mien, Nam Sơn, and Thang Tran Phenh had created impulsion for the development in Vietnam's oil painting in the next stages.

\section{References}

Dictionary of Vietnamese painters. (2008). Hanoi: MT Publisher.

Lê, T. H. (2007). Overview on Vietnam's oil painting arts. T/CMT, 172, 12-14.

Nguyễn, T. L. H. (2009). Summary on Chinese oil painting. T/CNCMT, 3(31), 55-58.

Nguyễn, T. M. (2008). The exhibition of Vietnam's lacquer pictures. T/CNCMT, 4(18), 11-17.

Phạm, C. S. (2004). Vietnam's traditional trade villages. Danang: The National Culture Publisher.

Thái, B. V. (1997). Overview on Vietnam's contemporary fine arts. Ho Chi Minh: ASEAN Fine Arts Contest of 1997 (Philip Morris Group's sponsorship).

Trần, T. Q. N. (2011). Training for traditional fine artists-Necessity and difficulties. T/CMT, 17.

Trang, T. H. (2008). Vietnam's lacquer painting along traditions and modernity. T/CNCMT, 4(18), 6-10. 